\title{
Augmented Lagrangian Algorithm for Hydrothermal Scheduling
}

\author{
R. Subramani ${ }^{1, *}$ and C.Vijayalakshmi ${ }^{2}$ \\ ${ }^{1}$ Department of Mathematics, St. Joseph's College of Engineering, Chennai \\ ${ }^{2}$ SAS, Mathematics Division, VIT University, Chennai
}

\begin{abstract}
This paper mainly deals with a new algorithm for solving hydrothermal scheduling problem with transmission and environmental constraints using Augmented Lagrangian(AL) method. Hydrothermal scheduling is a most important task in power management system. Transmission capacity and environmental constraints are relaxed by using Lagrangian multipliers. The existing methods are provided suboptimal solutions from the computational burden due to the large number of variables involved in the problem. This paper ensures efficient technique that involves a reduced number of decision variables for hydrothermal scheduling to reduce the total operating cost through AL method. The ultimate aim of hydrothermal scheduling is to ensure the optimal generation in both hydro and thermal units in order to fulfill the demands over a scheduled horizon. In this paper optimal hourly schedule for power generation in hydrothermal scheduling system applying Augmented Lagrangian Relaxation (ALR) technique.
\end{abstract}

Keywords: Augmented Lagrangian, Scheduling, Power demand, Hydro electric sources, Thermal generation cost.

Received on 03 May 2018, accepted on 20 May 2018, published on 12 June 2018

Copyright (C) 2018 R. Subramani and C.Vijayalakshmi et al., licensed to EAI. This is an open access article distributed under the terms of the Creative Commons Attribution licence (http://creativecommons.org/licenses/by/3.0/), which permits unlimited use, distribution and reproduction in any medium so long as the original work is properly cited.

doi: 10.4108/eai.12-6-2018.154815

"Corresponding author. Email:subramanivit@gmail.com

\section{Introduction}

In day to day life hydro-thermal scheduling is an important activity for electric utilities to meet the future demand. In overall energy utility of India, more than $70 \%$ of the electricity requirements are contributed from thermal sources. Hydro electric sources contributes a major share than any other sources whereas in India utilize below $24 \%$ of hydropower sources. In spite of this low share of the hydroelectric sources the overall generation of country is reduced due to more demand on peak hours of the customers. Studies on Hydro-thermal scheduling are carried out by many researchers. Some of the studies are mentioned here: The general structure of a unit commitment problem for power generation operation and management was discussed by Allen [1]. A fuel constrained based unit commitment problem was designed by Lee [2], Viramani
[3] implemented a Lagrangian Relaxation based and based on genetic algorithm Rudolf et al [4] designed a unit commitment problem for hydro thermal power system. Researchers have developed methods to solve hydro subproblems like Dynamic Programming (DP), network flow, and standard Mixed Integer Programming (MIP) methods. Lagrangian framework is a successful method discussed by Cohen et al [5], Shaw et al [6]. Xiaohong et al [7] proposed a nonlinear. approximation method for hydrothermal scheduling using Lagrangian Relaxation.

Baslis et al [8] proposed a MIP approach to the yearly scheduling problem of a mixed hydro thermal system. Rodrigues et al [9] solved the short-term scheduling problem of hydrothermal systems via Lagrangian Relaxation and augmented Lagrangian Methods. Borghett et al [10] proposed a MILP approach for shortterm hydro scheduling and unit commitment with headdependent reservoir. Cheng et al [11] analyzed the Comparison of Particle Swarm Optimization and Dynamic 
Programming for Large Scale Hydro Unit Load Dispatch. Pousinho et al [12] discussed the Scheduling of Hydro Producer Considering Head-De pendency, Price Scenarios and RiskAversion. Pérez-Díaz et al [13] conducted an Assessment of the Economic Impact of Environmental Constraints on Short Term Hydro power Plant Operation. PerézDíaz et al [14] analyzed a study on the Contribution of Regulation Reservoirs Considering Pumping Capability to Environmentally Friendly Hydro power Operation. The above mentioned studies helped the present study on arriving minimum production cost and maximum power utility period for the generating units.

Subramani et al [15-17] proposed Lagrangian Decomposition algorithms for power management systems. These algorithms are formulated based on generation, storage and distribution systems in various power plants. Thillainathan et al [18] combines LR simultaneously Evolutionary Algorithm (EA) to provide a hybrid algorithm for the real time energy environments. Hari et al [19] proposes a Ant Line Optimization algorithm whose inspiration from the hunting behaviour of ant lions, six step hunting behaviour is modelled using six easier operations for solution procedure with a variety of difficult constraints.

\section{Mathematical Model Formulation}

In the present study, the optimization model that have been designed for power generation by using thermal and hydro units with respect to various parameters and generating conditions of the power system. The objective of Hydrothermal scheduling is to generate the number of units that would satisfy the expected demand and to give the minimum power production cost in the planning time interval. Thesecalculation includes a set of energy constraints such as range of thermal and hydro units, water discharge rate, demand and energy consumption constraints, transmission loss constraints etc.

\subsection{Parameters}

$\mathrm{N}_{\mathrm{a}}-$ Set of all thermal units

$\mathrm{N}_{\mathrm{b}}$ - Set of all hydro units

$\mathrm{N}_{\mathrm{t}}$ - Total Study intervals (in hrs)

$\mathrm{k}$ - Set of all time slots

$\mathrm{N}$ - Total number of (Thermal and Hydro) units

$\mathrm{C}_{\mathrm{i}} \mathrm{P}_{\mathrm{i}}(\mathrm{k})$ - Thermal generation cost

$\mathrm{FC}_{\mathrm{i}}-$ Fuel cost for thermal unit $\mathrm{i}$

$\mathrm{C}_{\mathrm{si}}(\mathrm{k})-$ Startup cost for unit $\mathrm{i}$ at $\mathrm{k}$

$\mathrm{C}_{\mathrm{sd}} \mathrm{i}(\mathrm{k})$ - Shut down cost for unit $\mathrm{i}$ at $\mathrm{k}$

$\mathrm{C}_{\mathrm{m}}(\mathrm{k})$ - Maintenance cost for unit $\mathrm{i} \mathrm{k}$

$\mathrm{P}_{\mathrm{i}}(\mathrm{k})$ - Power output of thermal unit $\mathrm{i}$ at $\mathrm{k}$ (MW)

$\mathrm{P}_{\mathrm{j}}(\mathrm{k}) \quad-$ Power output of hydro unit $\mathrm{j}$ at $\mathrm{k}(\mathrm{MW})$

$\mathrm{P}_{\mathrm{i}}^{\max }(\mathrm{k})$-Upper limits of thermal units $\mathrm{i}$ in time slot $\mathrm{k}(\mathrm{MW})$

$\mathrm{P}_{\mathrm{i}}^{\min }(\mathrm{k})$-Lower limits of thermal units $\mathrm{i}$ in time slot $\mathrm{k}(\mathrm{MW})$

$\mathrm{P}_{\mathrm{j}}^{\max }(\mathrm{k})$ - Upper limits of hydro units $\mathrm{j}$ in time slot $\mathrm{k}(\mathrm{MW})$

$\mathrm{P}_{\mathrm{j}}{ }^{\min }(\mathrm{k})$ - Lower limits of hydro units $\mathrm{j}$ in time slot $\mathrm{k}(\mathrm{MW})$
$P_{R}(k)$-Spinning reserved requirement of unit $i$ at time slot $k$ (MW)

$\mathrm{P}_{\mathrm{D}}(\mathrm{k})$ - Load demand for whole System (MW)

$\mathrm{P}_{\mathrm{L}}(\mathrm{k})$ - System loss at time slot k (MW)

$\mathrm{W}_{\mathrm{D}}(\mathrm{k})$ - Discharged water for hydro generation in unit $\mathrm{j}$ at $\mathrm{k}(\mathrm{MW})$

Wv j - Available volume of water in hydro unit $\mathrm{j}(\mathrm{MW})$

$\mathrm{W}_{\mathrm{Fj}}(\mathrm{k})$ - Rate of water flow in hydro unit $\mathrm{j}$ at $\mathrm{k}$

$\mathrm{P}_{\mathrm{t}}(\mathrm{k})$ - Power flow in transmission line $\mathrm{t}$ at $\mathrm{k}(\mathrm{MW})$

$\mathrm{P}_{\mathrm{t}}^{\max }(\mathrm{k})$ - Upper limit of power flow unit $\mathrm{i}$ at time slot $\mathrm{k}$ (MW)

$\mathrm{P}_{\mathrm{t}}{ }^{\min }(\mathrm{k})$ - Lower limits of power flow unit $\mathrm{i}$ at time slot $\mathrm{k}$ (MW)

$\mathrm{N}_{\mathrm{a}}{ }^{\text {on/off }}-\mathrm{On} / \mathrm{Off}$ time duration for unit $\mathrm{i}$ at $\mathrm{k}$

$T_{i}{ }^{\text {on/off }}-$ Minimum on/off time for unit $i$

$\mathrm{ER}_{\mathrm{i}}-$ Emission rate

$\mathrm{H}_{\mathrm{i}} \quad$ - Heat function for the thermal unit i (lb/Mbtu)

EM - Maximum emission rate for the whole system over $\mathrm{Nt}$

$\mathrm{I}_{\mathrm{i}}(\mathrm{k})$ - Commitment unit $\mathrm{i}$ at time slot $\mathrm{k}$

$\lambda_{\mathrm{i}}, \mu_{\mathrm{j}}$ - Lagrangian Multipliers

\subsection{Optimization Model Formulation}

Hydrothermal generation scheduling can be formulated as a Non Linear Programming Problem (NLPP) based on the energy constraints and various system parameters. The objective of these scheduling is to minimize the cost of power produced by generation units Given a power station that contains $\mathrm{Na}$ thermal units and $\mathrm{Nb}$ hydro units the best generation commitment at each time $\mathrm{k}$ over a time horizon $\mathrm{Nt}$ are calculated. Cost optimization consists of startup cost, normal operational cost maintenance cost and shutdown costs. Since the marginal costs are so small for the hydro electric generation therefore they are negligible. Hence the objective function is defined by $\mathrm{f}: \wp \times \mathrm{I} \rightarrow \mathfrak{R}\left(\wp \subset \mathfrak{R}^{\mathrm{m} \times \mathrm{n}}, \mathrm{I}=\{0\right.$ or 1$\}^{\mathrm{m} \times \mathrm{na}}$ where $\mathrm{n}$ and $\mathrm{n}_{\mathrm{a}}$ are denoted by the number of generated units in Na and $N=N_{a} \cup N_{b}$ respectively).

$$
\left.f(\wp, I)=\sum_{k=1}^{N t} \mid \sum_{i=1}^{N a} C_{i}\left(P_{i}(k)\right) I_{i}(k)+I_{i}(k)\left(1-I_{i}(k)\right) \times C_{s i}(k)+C_{s d i}(k)+C_{m i}(k)\right\rfloor+\sum_{j=1}^{N b} C_{m j}(k)
$$

where $\wp$ is a $\mathrm{m} \times \mathrm{n}$ matrix each row of $\wp$ represents the power loading units (both thermal and hydro) at each time hour in $N_{t}$ and $I$ is $m \times n_{t}$ each row of this represents the status of thermal units at each hour in Nt. It is a nonconvex mixed integer non linear programming problem. Fuel cost for thermal unit is calculated by array equation numbers.

$$
C_{i} P_{i}(k)=x_{1}+y_{1} F_{i}+z_{1} F_{i}^{2} \quad i \in \mathrm{Na}
$$

Subject to the Constraints

$$
\begin{aligned}
& \text { System Power Balance Constraints: } \\
& \qquad \sum_{i, j \in N} I_{i}(k) P_{i}(k)=P_{D}(k)
\end{aligned}
$$

(System Demand constraint) 


$$
\sum_{i=1}^{N a} P_{i}^{\max }(k) I_{i}(k)+\sum_{j=1}^{N b} P_{j}^{\max }(k) I_{j}(k)-P_{D}(k)-P_{L}(k)=0
$$

(Spinning Reserved constraint)

Transmission loss can be calculated by

$$
P_{L}(k)=\sum_{i=1}^{N a+N b} \sum_{j=1}^{N a+N b} P_{i}(k) L_{i j} P_{j}(k)+\sum_{i=1}^{N a+N b} L_{0 i} P_{i}(k)+L_{00}
$$

Where $\mathrm{L}_{\mathrm{ij}}, \mathrm{L}_{0 \mathrm{i}}, \mathrm{L}_{00}$ are the loss formula coefficients of the transmission lines.

$$
\begin{aligned}
& \text { Spinning reserved requirement: } \\
& \sum_{i=1}^{N a} P_{i}^{\max }(k) I_{i}(k)+\sum_{j=1}^{N b} P_{j}^{\max }(k) I_{j}(k) \geq P_{D}(k)+P_{R}(k)
\end{aligned}
$$

\section{Unit Generation limit:}

$$
\mathrm{P}_{\mathrm{i}}^{\text {min }} \leq \mathrm{P}_{\mathrm{i}}(\mathrm{k}) \leq \mathrm{P}_{\mathrm{i}}^{\text {max }} \quad \mathrm{i}=1,2,3, \ldots, \mathrm{Na}
$$

(Thermal unit bounds)

$$
\mathrm{P}_{\mathrm{j}}^{\min } \leq \mathrm{P}_{\mathrm{j}}(\mathrm{k}) \leq \mathrm{P}_{\mathrm{j}}^{\max } \quad \mathrm{j}=1,2,3, \ldots, \mathrm{N}_{\mathrm{b}}
$$

(Hydro unit bounds)

Relationship between water discharge and Power flow:

Water availability is

$$
\sum_{k=1}^{N t} \sum_{j=1}^{N b} W_{D j}(k) .1 h r=W_{v j}
$$

(Water conservation constraint)

The rate of water flow is calculated by

$$
\mathrm{W}_{\mathrm{Fj}}(\mathrm{k})=x_{2}+y_{2} F_{j}+z_{2} F_{j}^{2}
$$

where $\mathrm{x}_{2}, \mathrm{y}_{2}, \mathrm{z}_{2}$ are water discharge coefficients for hydro unit j.

\section{Startup and Shut down time for Thermal units:}

$\left(\mathrm{N}_{\mathrm{a} i}{ }^{\text {on }}(\mathrm{k}-1)-\mathrm{T}_{\mathrm{i}}{ }^{\text {on }}\right) .\left(\mathrm{I}_{\mathrm{i}}(\mathrm{k}-1)-\mathrm{I}_{\mathrm{i}}(\mathrm{k})\right) \geq 0$
$\left(\mathrm{~N}_{\mathrm{a} i}{ }^{\text {off }}(\mathrm{k}-1)-\mathrm{T}_{\mathrm{i}}{ }^{\text {off }}\right) .\left(\mathrm{I}_{\mathrm{i}}(\mathrm{k})-\mathrm{I}_{\mathrm{i}}(\mathrm{k}-1)\right) \geq 0$

\section{Transmission line capacity limit:}

$$
\mathrm{P}_{\mathrm{t}}^{\min }(\mathrm{k}) \leq \mathrm{P}_{\mathrm{t}}(\mathrm{k}) \leq \mathrm{P}_{\mathrm{t}}^{\max }(\mathrm{k})
$$

\section{Emission Constraints:}

$$
\begin{aligned}
& \sum_{k=1}^{N t} \sum_{i=1}^{N a} E R_{i} H_{i}\left(p_{i}(k)\right) I_{i}(k) \leq E M \\
& \sum_{k=1}^{N t} q_{i} C_{i}\left(P_{i}(k)\right) \leq E M(k)
\end{aligned}
$$

The $\mathrm{NOx}, \mathrm{SO}_{2}, \mathrm{CO}_{2}$ emission objective can be defined as:

$$
\begin{aligned}
& F_{1 i}(k)=\theta_{1}+\tau_{1} F_{i}+\delta_{1} F_{i}^{2}(K g / h r) \\
& F_{2 i}(k)=\theta_{2}+\tau_{2} F_{i}+\delta_{2} F_{i}^{2}(K g / h r) \\
& F_{3 i}(k)=\theta_{3}+\tau_{3} F_{i}+\delta_{3} F_{i}^{2}(K g / h r)
\end{aligned}
$$

where $\theta_{1}, \tau_{1}, \delta_{1}$ are the coefficients for NOx emission; $\theta_{2}, \tau_{2}, \delta_{2}$ are the coefficients for $\mathrm{SO}_{2}$ emission and $\theta_{3}, \tau_{3}, \delta_{3}$ are $\mathrm{CO}_{2}$ emission coefficients.

\section{Augmented Lagrangian (AL) Method}

An AL method is implemented to solve this problem. Therefore the primal problem becomes, From the proposed problem both thermal and hydro units are independent but together must met the overall system demand. The total operating cost to be minimized hence this attains Lagrangian Relaxation technique to exploit the decomposability of the proposed problem. The solution of the subproblems are piecewise linear cost functions which attains the optimal solution only in bounds and it may oscillates the small changes of the multipliers. To overcome this difficulty Lagrangian a quadratic penalty function is added associated with demand constraint is known as Augmented Lagrangian Relaxation technique. The Augmented Lagrangian function for the proposed problem is denoted by,

$$
\begin{aligned}
L(U, \lambda, \mu, c)= & \sum_{k=1}^{N t} \sum_{i=1}^{N a} C_{i} P_{i}(k)+\sum_{k=1}^{N_{t}} \lambda_{i}\left[P_{D}(k)+P_{L}(k)-\sum_{i=1}^{N a} P_{i}^{\max }(k)-\sum_{j=1}^{N b} P_{j}^{\max }(k)\right] \\
& +\sum_{j=1}^{N b} \mu_{j}\left[\sum_{k=1}^{N h} k\left(W_{F j}+\alpha_{1}-W_{v j}\right)\right]+\frac{C_{k}}{2} \sum_{k=1}^{N H}\left[P_{D}(k)+P_{L}(k)-\sum_{i=1}^{N a} P_{i}^{\max }(k)-\sum_{j=1}^{N b} P_{j}^{\max }(k)\right]^{2} \\
& +\frac{C_{j}}{2} \sum_{j=1}^{N b}\left[\sum_{k=1}^{N t}\left(W_{F j}+\alpha_{2}-W_{v j}\right)\right]^{2}
\end{aligned}
$$

Here $C_{k}, C_{j}$ are positive penalty coefficients and $\alpha_{1}, \alpha_{2}$ are the slack variables. The quadratic penalty terms in are relaxed by Lagrangian decomposition.

\section{Numerical Calculations and Graphical Representations}

The proposed ALR method is solved in MATLAB2010a, the computations were done in HP Laptop. Computational results enforces from best among 50 runs of the ALR algorithm. Minimum, maximum limits and fuel cost for the generation of thermal units calculated by using ALR method over hourly planning horizon and it is depicted in Table 1.

Table 1. Generation cost for thermal units

\begin{tabular}{cccccc}
\hline Plant & $\begin{array}{c}\mathrm{X}_{1} \\
(\$ / \mathrm{MW} \\
\mathrm{hr})\end{array}$ & $\begin{array}{c}\mathrm{y}_{1} \\
(\$ / \mathrm{MW} \\
\mathrm{hr})\end{array}$ & $\begin{array}{c}\mathrm{Z}_{1} \\
(\$ / \mathrm{MW} \\
\mathrm{hr})\end{array}$ & $\begin{array}{c}\mathrm{P}_{\mathrm{i}}{ }^{\min }(\mathrm{k}) \\
(\mathrm{MW})\end{array}$ & $\begin{array}{c}\mathrm{P}_{\mathrm{i}}{ }^{\max }(\mathrm{k}) \\
(\mathrm{MW})\end{array}$ \\
\hline 1 & 0.01 & 0.1 & 100 & 50 & 200 \\
2 & 0.02 & 0.1 & 120 & 40 & 170 \\
3 & 0.01 & 0.2 & 150 & 30 & 215 \\
\hline
\end{tabular}


For optimal hydrothermal generation schedule in both plants met the load demand and transmission losses are calculated using ALR algorithm is shown in Table 2.and Table 3 . over one day hourly planning horizon.

Table 2. Load demand

\begin{tabular}{cccccc}
\hline Hour & $\begin{array}{c}\mathrm{PD}_{\mathrm{D}} \\
(\mathrm{MW})\end{array}$ & Hour & $\begin{array}{c}\mathrm{PD}_{\mathrm{D}} \\
(\mathrm{MW})\end{array}$ & Hour & $\begin{array}{c}\mathrm{PD}_{\mathrm{D}} \\
(\mathrm{MW})\end{array}$ \\
\hline 1 & 175 & 9 & 440 & 17 & 425 \\
2 & 190 & 10 & 475 & 18 & 400 \\
3 & 220 & 11 & 525 & 19 & 375 \\
4 & 280 & 12 & 550 & 20 & 340 \\
5 & 320 & 13 & 565 & 21 & 300 \\
6 & 360 & 14 & 540 & 22 & 250 \\
7 & 390 & 15 & 500 & 23 & 200 \\
8 & 410 & 16 & 450 & 24 & 180 \\
\hline
\end{tabular}

Table 3. Generation cost for hydro units

\begin{tabular}{ccccccc}
\hline $\begin{array}{c}P l \\
\text { ant }\end{array}$ & $P_{j}^{\text {min }}(k)$ & $P_{j}^{\text {max }}(k)$ & $\begin{array}{c}\text { Water } \\
\text { Volume } \\
\left(m^{3}\right)\end{array}$ & $x_{j}$ & $y_{j}$ & $z_{j}$ \\
\hline 1 & 50 & 200 & 25000 & 0.01 & 0.10 & 100 \\
\hline
\end{tabular}

Figure1. reflects that the system demand over one day scheduling period and it attains maximum in $13^{\text {th }}$ hour. For hydro units the corresponding power generation limits and water availability and its discharge rate coefficients are calculated in table -3

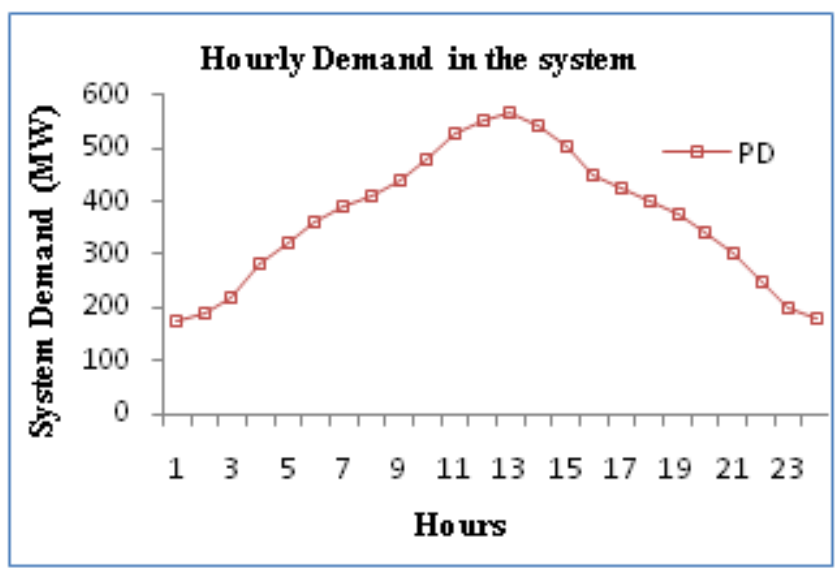

Figure 1. Hourly demand of the system
The efficiency of the Augmented Lagrangian Relaxation Technique is tested for a hydrothermal plant. The purpose of applying Augmented Lagrangian method is minimize the loss of the system as well as maximize the generation utility over a planning horizon. In order to fulfill the demand (load) of the system generation scheduling offers to schedule the units for generation by satisfying all the system constraints. In spite of achieving maximum profit for the power generating utility supply and demand are utilized in a reliable manner.

Fig 2 classifides that the unitwise generation of both thermal and hydro units; the maximum load is utilized by using ALR technique over one day planning horizon.

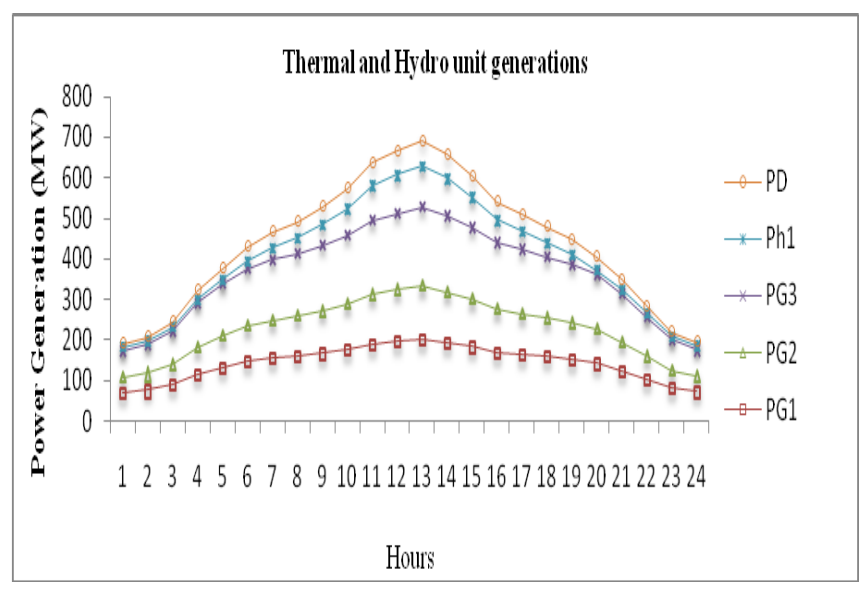

Figure 2. Unit wise Generation

The energy losses are calculated in quadratic nature over hourly planning horizon and it is depicted in Table 4.

Table 4. Power loss obtained from AL Technique

\begin{tabular}{|c|c|c|c|c|c|}
\hline \multirow{2}{*}{$\begin{array}{l}\text { Ho } \\
\text { ur }\end{array}$} & \multicolumn{3}{|c|}{ Thermal Generation } & \multirow{2}{*}{$\begin{array}{c}\text { Hydro } \\
\text { Generati } \\
\text { on } \\
\mathrm{P}_{\mathrm{h} 1}(\mathrm{MW})\end{array}$} & \multirow{2}{*}{$\begin{array}{l}\text { Loss } \\
\text { (MW) }\end{array}$} \\
\hline & $\mathrm{P}_{\mathrm{G} 1}(\mathrm{MW})$ & $\begin{array}{c}\mathrm{P}_{\mathrm{G} 2} \\
\text { (MW) }\end{array}$ & $\mathrm{P}_{\mathrm{G} 3}(\mathrm{MW})$ & & \\
\hline 1 & 68.1356 & 40.0000 & 64.0655 & 10.0000 & 7.2007 \\
\hline 2 & 77.1462 & 41.6310 & 70.0654 & 10.0000 & 8.8426 \\
\hline 3 & 88.9214 & 50.2145 & 83.0333 & 10.0000 & 12.1691 \\
\hline 4 & 114.2141 & 67.3381 & 109.2003 & 10.0000 & 20.7527 \\
\hline 5 & 131.7539 & 78.4389 & 127.8284 & 10.0741 & 28.0956 \\
\hline 6 & 145142 & 88.5791 & 141.4943 & 17.8482 & 34.4359 \\
\hline 7 & 154.6471 & 94.8724 & 148.4014 & 29.9173 & 37.8385 \\
\hline 8 & 160.5308 & 98.7054 & 153.0133 & 38.0547 & 40.3041 \\
\hline 9 & 165.1055 & 102091 & 162.3226 & 50.2454 & 43.8825 \\
\hline
\end{tabular}




\begin{tabular}{|c|c|c|c|c|c|}
\hline 10 & 175.8352 & 113.1778 & 169.6516 & 64.9265 & 48.591 \\
\hline 11 & 188.4399 & 123.3503 & 183.0102 & 81154 & 55.915 \\
\hline 12 & 194.9369 & 129.0775 & 189.3461 & 92.4565 & 59.915 \\
\hline 13 & 200.0000 & 134.1211 & 193.8283 & 100.00 & 62.949 \\
\hline 14 & 191.6835 & 127.1509 & 184970 & 92.6519 & 57.983 \\
\hline 15 & 182.4302 & 118.2798 & 173102 & 75.2374 & 52.257 \\
\hline 16 & 167.5452 & 108.4111 & 164.5151 & 54.6059 & 45.077 \\
\hline 17 & 162.1553 & 102.7916 & 158.2515 & 43.8912 & 42.089 \\
\hline 18 & 157.9871 & 96312 & 150.7118 & 33.8157 & 39.944 \\
\hline 19 & 149.6308 & 92.4476 & 144.9175 & 23.9481 & 35.944 \\
\hline 20 & 141.1155 & 85.3907 & 135.2588 & 10.2154 & 31.980 \\
\hline 21 & 123.4245 & 72.6379 & 118.2341 & 10.0000 & 24.296 \\
\hline 22 & 101.6896 & 57.8784 & 96686 & 10.0000 & 12363 \\
\hline 23 & 80.5810 & 44.9917 & 74.2655 & 10.0000 & 9.83 \\
\hline 24 & 71.7041 & 40.0000 & 60655 & 10.0000 & 7.7 \\
\hline 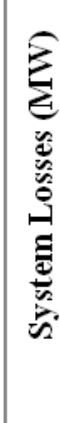 & $\left.\begin{array}{c}70 \\
60 \\
60\end{array}\right]$ & $\begin{array}{lllll}5 & 7 & 9 & 1\end{array}$ & $\begin{array}{lll}13 & 15 & 17\end{array}$ & 192123 & \\
\hline
\end{tabular}

Figure 1. Hourly system loss

Figure. 3 reveals that the calculated overall system losses (MW) over one day planning horizon. From this maximum loss are obtained in $13^{\text {th }}$ hour which leads up to $62.9491 \mathrm{MW}$ energy losses due to peak demand of the consumers.

Figure. 4 ensures that the water discharge rate for a single hydro generation unit based on ALR technique over one day planning horizon.

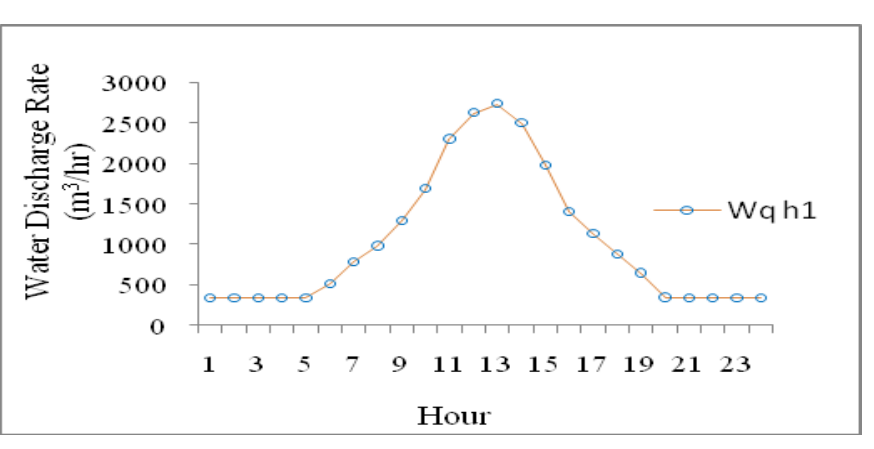

Figure 4. Hourly water discharge rate

Table 5. ensures that the generation cost for one hydro unit and three thermal units obtained by ALR technique. From the below table it is clear that generation cost is increased from $1-13^{\text {th }}$ hours based on the peak demand and it is decreased from $13-24$ due to off peak demand.

Table 5. Generation cost for thermal and hydro plants over hourly planning horizon

\begin{tabular}{|c|c|c|c|c|c|}
\hline $\begin{array}{l}\text { Ho } \\
\text { urs }\end{array}$ & $\begin{array}{c}F_{1} \\
(\$ / \mathrm{hr})\end{array}$ & $\begin{array}{c}F_{2} \\
(\$ / h r)\end{array}$ & $\begin{array}{c}F_{3} \\
(\$ / h r)\end{array}$ & $\begin{array}{c}F_{t} \\
(\$ / \mathrm{hr})\end{array}$ & $\begin{array}{c}W q_{h 1} \\
\left(m^{3} / h r\right)\end{array}$ \\
\hline 1 & 153.2382 & 150000 & 203.8570 & 513.0952 & 340000 \\
\hline 2 & 167.2299 & 158.8259 & 213.1048 & 539.1606 & 340000 \\
\hline 3 & 187.9623 & 175.4514 & 235.5519 & 598.9656 & 340000 \\
\hline 4 & 241.8700 & 217.4222 & 291.0872 & 750.3794 & 340000 \\
\hline 5 & 287662 & 250.8972 & 338.9666 & 876.300 & 347.5712 \\
\hline 6 & 329.3155 & 285.7832 & 378.5053 & 993.604 & 510775 \\
\hline 7 & 354.6219 & 309.5029 & 399.9101 & 1064.0349 & 792.0487 \\
\hline 8 & 373.7544 & 324.7256 & 414.7333 & 1113.2133 & 987.9836 \\
\hline 9 & 389.1088 & 352285 & 445.9508 & 1191.2881 & 129384 \\
\hline 10 & 427638 & 387.5019 & 471.7471 & 1280128 & 1691.457 \\
\hline 11 & 473.9399 & 436409 & 521.5294 & 1432.1102 & 2307.260 \\
\hline 12 & 499.4977 & 461279 & 543887 & 1512.0143 & 2627.361 \\
\hline 13 & 520.0000 & 493.1817 & 564.4598 & 1577.6415 & 2740.000 \\
\hline 14 & 485941 & 450622 & 535.1106 & 1477.7669 & 2508.101 \\
\hline 15 & 451.0509 & 411.6302 & 491148 & 1358.7959 & 1984.388 \\
\hline
\end{tabular}




\begin{tabular}{|c|c|c|c|c|}
\hline 16 & 397.4685 & 365.9007 & 453.5553 & 1219245 \\
\hline 17 & 379.1589 & 341.6012 & 432.0856 & 1152.8457 \\
\hline 18 & 365.3979 & 314148 & 407.2829 & 1089.0956 \\
\hline 19 & 338.8569 & 300.1758 & 388.9942 & 1028.0269 \\
\hline 20 & 313.2474 & 274.3705 & 360.0013 & 947.6192 \\
\hline 21 & 264.6784 & 232.7892 & 313.4398 & 810.9074 \\
\hline 22 & 213.5766 & 192.7861 & 262.7819 & 669.1446 \\
\hline 23 & 172.9911 & 164.9841 & 229.0067 & 569819 \\
\hline 24 & 158.5851 & 150000 & 298596 & 611.4447 \\
\hline \multicolumn{5}{|c|}{ Table - 6 Comparative study results } \\
\hline \multicolumn{2}{|r|}{ Method } & \multicolumn{2}{|c|}{$\begin{array}{l}\text { Total Fuel Cost } \\
\qquad(\$)\end{array}$} & $\begin{array}{l}\text { Computational } \\
\text { Time (Sec) }\end{array}$ \\
\hline \multicolumn{2}{|r|}{ PSO } & \multicolumn{2}{|c|}{24378.7028} & 15.32 \\
\hline & GA & \multicolumn{2}{|c|}{24378.0589} & 18.14 \\
\hline & ALR & \multicolumn{2}{|c|}{24337.7032} & 10.23 \\
\hline
\end{tabular}

minimizes the computational burden. The reservoir level and

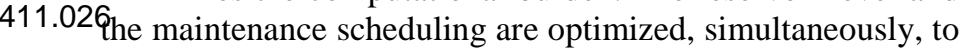
minimize the thermal generation complement and to 133.410naximize the future water value. Test results shows that this algorithm is fast efficient and provides reasonable results in 884.924 practical size systems.

653.3727

\section{References}

[1] Book :J. ALLEN WOOD, F. BRUCE and WOLLENBRG, (2013) Power Generation Operation and Control, $2^{\text {nd }}$ ed. (John Wiley \& Sons, New York. ISBN: 978-0-471-79055-6)

[2] Journal article: F.N. LEE (1989) A Fuel-Constrained Unit Commitment Method, IEEE Transaction on Power Systems, Vol.4(3): pp. $1208-1218$.

[3] Journal article: S.VIRAMANI, K. CADRIN, S. IMHOF and 340000 MUKHERJEE, (1989) Implementation of a Lagrangian Relaxation Based Unit Commitment Problems, IEEE Transaction on Power Systems, Vol. 4(4) : pp. $692-698$.

[4] Journal article: R. RUDOLF and BAYRLEITHNER, (1999) A Genetic Algorithm for Solving the Unit Commitment Problem of a Hydro Thermal Power System, IEEE Transactions on Power Systems, Vol. 14(4) : pp. 1460-1468.

[5] Journal article: I. COHEN and S.H. WAN, (1985) An Algorithm for Scheduling a Large Pumped Storage Plant, IEEE Transaction on Power Apparatus and Systems, Vol. PAS-104 (8) : pp. 2099 - 2104.

[6] Journal article: J.J. SHAW and D.P. BERTSEKAS, (1985) Optimal Scheduling of Large Hydro thermal Power Systems, IEEE Transactions on Power Apparatus and Systems, Vol. PAS-104, pp.286 -293

[7] Journal article: X. GUAN and P.B. LUH, (1995) Nonlinear Approximation method in Lagrangian Relaxation based algorithms for Hydrothermal Scheduling, IEEE Transactions on Power Systems, Vol. 10(2) : pp. $772-778$.

[8] conference: C.G. BASLIS and A.G. BAKIRTZIS, (2008) A MIP Approach to the Yearly Scheduling Problem of a Mixed Hydro thermal System, In Proceedings of the $5^{\text {th }}$ International conference on the European Electricity Market, ( Lisboa, Portugal ) pp. $1-6$. algorithms such as Particle Swam Optimization (PSO) and Genetic Algorithm (GA). Based on the numerical calculations and graphical representations proposed Augmented Lagrangian Relaxation techniques leads to the acceptable solutions. Particle Swarm Optimization and Genetic Algorithm are the populations based soft computing techniques, attains convergence limit at 15.32 seconds and 18.14 seconds whereas proposed ALR technique attains convergence limit in 10.23 seconds with 50 iterations.

\section{Conclusion}

In order to solve hydrothermal generation and scheduling problem a new ALR algorithms has been proposed as a Nonlinear Integer Programming Problem. With the help of Lagrangian multipliers the complicating constraints such as demand and reserve requirements are decomposed. These Lagrangian multipliers act as a price resources to concentrate the generation limits and reserve contribution in both individual and hybrid configurations. The algorithm has been modified to reduce the number of variables and hence problem

[9] Journal article: R.N. RODRIGUES, E.C. FINARDI and E.L. SILVA, (2012) Solving the Short-Term Scheduling Problem of Hydro thermal Systems Via Lagrangian Relaxation and Augmented Lagrangian, Mathematical problems in Engineering, Vol. 2012, Article ID 856178, 18 pages.

10] Journal article: A.I. BORGHETT, D'AMBROSI, A. LODI and S. MARTELLO, (2008) An MILP Approach for ShortTerm Hydro Scheduling and Unit Commitment with HeadDependent Reservoir, IEEE Transactions on Power Systems, Vol.23(3) : pp.1115-1124.

[11] Journal article: C. CHENG, S. LIAO, Z. TANG and M. ZHAO, (2009) Comparison of Particle Swarm Optimization and Dynamic Programming for Large Scale Hydro Unit Load Dispatch, Energy Conversion and Management, Vol.50(12) : pp.3007-3014.

[12] Journal article: H.M.I. POUSINHO, V.F. MENDES and J.P.S. CATALO, (2012) Scheduling of a Hydro Producer Considering Head-Dependency, Price Scenarios and RiskAversion, Energy Conversion and Management, Vol. 56, pp. $96-103$.

[13] Journal article: J.I. PÉREZ-DÍAZ and J.R. WILHELMI, (2010) Assessment of the Economic Impact of 
Environmental Constraints on Short Term Hydropower Plant Operation, Energy Policy, Vol. 38(12) : pp.7960 -7970.

[14] Journal article : J.I. PERÉZ-DÍAZ, R. MILLÁN, D. GARCÍA, I. GUISÁNDEZ and J.R. WILHELMI, (2011) Contribution of Regulation Reservoirs Considering Pumping Capability to Environmentally Friendly Hydropower Operation, Energy, Vol.48(1) : pp. $144-152$.

[15] Journal article : R. SUBRAMANI and C. VIJAYALAKSHMI, (2016) Design of Lagrangian Decomposition Model for Energy Management using SCADA Systems, Smart Innovation, Systems and Technologies, Vol. 49: pp. $353-361$.

[16] Journal article : R. SUBRAMANI and C. VIJAYALAKSHMI, (2016) Implementation of an Optimization Model for Pump Scheduling, International Journal of Pure and Applied Mathematics, Vol. 109(5) : pp. 41 - 49.

[17] Journal article : R. SUBRAMANI and C. VIJAYALAKSHMI, (2016) A Review on Advanced Optimization Techniques, ARPN Journal of Engineering and Applied Sciences, Vol. 11(19) : pp. $11675-11683$.

[18] Journal article : T. LOGENTHIRAN, W.L. WOO and V.T. PHAN (2015), Lagrangian Relaxation Hybrid with Evolutionary Algorithm for Short-term Generation Scheduling, Electrical power and Energy Systems, Vol. 64 : pp.356 - 364.

[19] Journal article : H.M. DUBEY, M. PANDIT and B.K. PANIGRAHI, (2016) Ant lion Optimization for Short-term Wind Integrated Hydrothermal Power Generation Scheduling, Electrical Power and Energy Systems, Vol. 83 : pp. 158-174. 